\title{
Application of General Circulation Models to Assess the Potential Impact of Climate Change on Potential Distribution and Relative Abundance of Melanoplus sanguinipes (Fabricius) (Orthoptera: Acrididae) in North America
}

\author{
O. Olfert, ${ }^{1}$ R. M. Weiss, ${ }^{1}$ and D. Kriticos ${ }^{2}$ \\ ${ }^{1}$ Agriculture and Agri-Food Canada, Saskatoon Research Centre, 107 Science Place, Saskatoon, SK, Canada S7N 0X2 \\ ${ }^{2}$ CSIRO Entomology, GPO Box 1700, Canberra, ACT 2601, Australia \\ Correspondence should be addressed to O. Olfert, owen.olfert@agr.gc.ca
}

Received 1 June 2010; Revised 6 August 2010; Accepted 7 August 2010

Academic Editor: Michel Lecoq

Copyright ( $\odot 2011$ O. Olfert et al. This is an open access article distributed under the Creative Commons Attribution License, which permits unrestricted use, distribution, and reproduction in any medium, provided the original work is properly cited.

Climate is the dominant factor determining the distribution and abundance of most insect species. In recent years, the issue of climatic changes caused by human activities and the effects on agriculture has raised concern. General circulation model scenarios were applied to a bioclimatic model of Melanoplus sanguinipes to assess the potential impact of global warming on its distribution and relative abundance. Native to North America and widely distributed, M. sanguinipes is one of the grasshopper species of the continent most responsible for economic damage to grain, oilseed, pulse, and forage crops. Compared to predicted range and distribution under current climate conditions, model results indicated that $M$. sanguinipes would have increased range and relative abundance under the three general circulation model scenarios in more northern regions of North America. Conversely, model output predicted that the range of this crop pest could contract in regions where climate conditions became limiting.

\section{Introduction}

Climate is the dominant factor determining the distribution and abundance of most insect species [1]. The issue of climatic changes caused by human activities and the effects on agriculture has raised concern in recent years. The overall global temperature has increased $0.7^{\circ} \mathrm{C}$ over the last 100 years, with the 1990's being the warmest decade on record [2]. Climate change scenarios using low greenhouse gas emissions suggest that temperatures will increase by $1-3^{\circ} \mathrm{C}$ over the next 100 years and temperatures have been predicted to increase by $3.5-7.5^{\circ} \mathrm{C}$ for scenarios with high gas emission [3]. However, Walther et al. [4] suggest that species respond to regional changes that are highly heterogeneous and not to approximated global averages. Many species have already responded to regional conditions that have occurred during the 20th century. In a study of 694 animal and plant species, Root et al. [5] investigated the change in timing of events over the past 50 years and reported that changes in timing of spring events (breeding, blooming) occurred 5.1 days earlier per decade. Warming conditions may impact grasshopper populations by extending the growing season, altering the timing of emergence from overwintering sites, increasing growth and development rates, shorting generation times, increasing the numbers of eggs laid, and changing their geographic distribution $[6,7]$.

Analogue scenarios which make use of existing climate data are useful to identify geographic regions that may be susceptible to establishment of insects, when comparing the results of climate change scenarios to those regions where the species in question is already established [8]. However, the magnitude of predicted temperature change associated with climate change is not within the historical experience of modern agriculture. Hence, it is unlikely that we can use historical data as analogues to predict the impact of climate change on pest species. As a result, simulation models have been used to assess impact and related system vulnerability due to climate change. 
TABle 1: CLIMEX parameter values used to predict potential distribution and relative abundance of Melanoplus sanguinipes in North America.

\begin{tabular}{|c|c|c|}
\hline \multicolumn{3}{|c|}{ CLIMEX growth parameters } \\
\hline \multicolumn{3}{|c|}{ Temperature } \\
\hline DV0 & Limiting low average weekly temperature & $10.0^{\circ} \mathrm{C}$ \\
\hline DV1 & Lower optimal average weekly minimum temperature & $16.0^{\circ} \mathrm{C}$ \\
\hline DV2 & Upper optimal average weekly maximum temperature & $28.0^{\circ} \mathrm{C}$ \\
\hline DV3 & Limiting high average weekly maximum temperature & $32.0^{\circ} \mathrm{C}$ \\
\hline \multicolumn{3}{|l|}{ Moisture } \\
\hline SM0 & Limiting low soil moisture & 0.02 \\
\hline SM1 & Lower optimal soil moisture & 0.05 \\
\hline SM2 & Upper optimal soil moisture & 0.30 \\
\hline SM3 & Limiting high soil moisture & 0.70 \\
\hline \multicolumn{3}{|l|}{ Diapause } \\
\hline DPD0 & Diapause induction day length & $11 \mathrm{~h}$ \\
\hline DPT0 & Diapause induction temperature (average weekly minimum) & $11.0^{\circ} \mathrm{C}$ \\
\hline DPD1 & Diapause termination temperature (average weekly minimum) & $3.0^{\circ} \mathrm{C}$ \\
\hline $\mathrm{DPD}$ & Diapause development days & 120 \\
\hline DPSW & Summer or winter diapause & 0 \\
\hline \multicolumn{3}{|c|}{ CLIMEX Stress Parameters: } \\
\hline \multicolumn{3}{|l|}{ Cold stress } \\
\hline TTCS & Cold stress threshold (average weekly minimum temperature) & $-18.0^{\circ} \mathrm{C}$ \\
\hline THCS & Rate of cold stress accumulation & -0.0004 \\
\hline \multicolumn{3}{|l|}{ Heat stress } \\
\hline TTHS & Heat stress threshold (mean weekly maximum temperature) & $35.0^{\circ} \mathrm{C}$ \\
\hline THHS & Rate of heat stress accumulation & 0.008 \\
\hline \multicolumn{3}{|l|}{ Dry stress } \\
\hline SMDS & Dry stress threshold (mean weekly minimum soil moisture) & 0.020 \\
\hline HDS & Rate of dry stress accumulation & -0.003 \\
\hline \multicolumn{3}{|l|}{ Wet stress } \\
\hline SMWS & Wet stress threshold (mean weekly maximum soil moisture) & 0.7 \\
\hline HWS & Rate of wet stress accumulation & 0.001 \\
\hline
\end{tabular}

Bioclimate simulation models have been used successfully to predict the distribution and extent of insect establishment in new environments [9-12]. Bioclimatic modeling software, such as CLIMEX, enables the development of models that describe the potential distribution and relative abundance of a species based on climate [1,13]. CLIMEX derives an Ecoclimatic Index (EI) which describes the suitability of specific locations for species survival and reproduction. Model parameters include temperature (TI), diapause (DI), light (LI), moisture (MI), heat stress (HS), cold stress (CS), wet stress (WS), and dry stress (DS). The EI values are obtained by combining a Growth Index (GI) with stress indices (dry, wet, cold, and hot) that describe conditions that are unfavourable for growth.

Native to North America and widely distributed, Melanoplus sanguinipes (Fabricius) (Orthoptera: Acrididae) is responsible for more economic damage to grain, oilseed, pulse, and forage crops than any other grasshopper species [14-16]. A bioclimate model was developed to predict the potential distribution and relative abundance of M. sanguinipes, within Canada [17]. Ecological sensitivity analyses were then conducted using incremental scenarios for all combinations of temperature $(0,+1,+2,+3,+4,+5,+6$, and $+7^{\circ} \mathrm{C}$ of climate normal temperature for each grid) and of precipitation $(-60 \%,-40 \%,-20 \%,-10 \%, 0 \%$, $10 \%, 20 \%, 40 \%, 60 \%$ of climate normal precipitation for each grid). Compared to predicted range and distribution under current climate conditions, model results indicated that $M$. sanguinipes would have increased range and relative abundance for temperature increases between $1^{\circ} \mathrm{C}$ and $7^{\circ} \mathrm{C}$. The model predicted that the range of this crop pest could be extended to regions that are not currently used for agricultural production in North America. Mika et al. [18] stated that at an ecosystem level, climatic variables will vary both spatially and temporally. Therefore, they suggested that the widely accepted and more commonly used general circulation models (GCMs) should be used in conjunction with bioclimate models, rather than incremental scenarios. Further, they encouraged the application of multiple GCMs due to the variability of climate projections between models.

The objective of this study was to use the bioclimate model for M. sanguinipes [17] to assess the impact of three 
TABle 2: Baseline(CRU) and general circulation model (NCAR273 CCSM, MIROC-H, CSIRO MARK 3.0) scenarios and resulting Ecoclimatic Inex (EI), temperature (TI), moisture (MI), diapause (DI), growth index (GI), cold stress (CS), heat stress (HS), number of weeks GI was positive (Weeks GI Positive), and core distribution, for Melanoplus sanguinipes at six locations.

\begin{tabular}{|c|c|c|c|c|c|c|c|c|c|c|}
\hline Location & Scenario & EI & $\mathrm{TI}$ & MI & DI & GI & CS & HS & $\begin{array}{l}\text { Weeks GI } \\
\text { positive }\end{array}$ & $\begin{array}{c}\text { Core } \\
\text { distribution }\end{array}$ \\
\hline \multirow[t]{4}{*}{ Fairbanks, AK } & NCAR273 CCSM & 20.1 & 22.3 & 83.2 & 38.5 & 20.7 & 2.9 & 0 & 18.2 & 97 \\
\hline & CSIRO MARK 3.0 & 18.3 & 22.9 & 83.2 & 40.1 & 20.9 & 12.7 & 0 & 18 & 87.1 \\
\hline & MIROC-H & 18.2 & 21.5 & 87.3 & 37.7 & 20 & 8.6 & 0 & 17.1 & 91.3 \\
\hline & CRU & 5.4 & 12 & 88.6 & 33.1 & 11.1 & 54.2 & 0 & 13.9 & 45.7 \\
\hline \multirow[t]{4}{*}{ Peace River, AB } & NCAR273 CCSM & 23.8 & 34.2 & 71.9 & 42.1 & 23.8 & 0 & 0 & 20.7 & 97.3 \\
\hline & CSIRO MARK 3.0 & 29.2 & 33.2 & 77.9 & 43.4 & 29.4 & 0.1 & 0 & 22.4 & 98.8 \\
\hline & MIROC-H & 25 & 30.2 & 79.5 & 41.3 & 25 & 0 & 0 & 21.2 & 98.6 \\
\hline & CRU & 14.7 & 21.8 & 80.2 & 36.9 & 16.5 & 9.6 & 0 & 19 & 87.9 \\
\hline \multirow[t]{4}{*}{ Saskatoon, SK } & NCAR273 CCSM & 34.9 & 37.8 & 92.3 & 45.6 & 34.9 & 0 & 0 & 23.8 & 100 \\
\hline & CSIRO MARK 3.0 & 36.3 & 37.5 & 94.3 & 46.5 & 36.3 & 0 & 0 & 24.2 & 100 \\
\hline & MIROC-H & 35.2 & 36.6 & 91.7 & 44.6 & 35.2 & 0 & 0 & 23.3 & 100 \\
\hline & CRU & 26.7 & 30.7 & 96.1 & 41.8 & 28.8 & 8.2 & 0 & 21.8 & 91.8 \\
\hline \multirow[t]{4}{*}{ Gillette, WY } & NCAR273 CCSM & 24.4 & 29.9 & 96.9 & 48.8 & 24.4 & 0 & 0 & 19.7 & 100 \\
\hline & CSIRO MARK 3.0 & 24.1 & 30.1 & 98.2 & 50.2 & 24.9 & 0 & 3.9 & 18.3 & 96.1 \\
\hline & MIROC-H & 24.9 & 30.4 & 95.8 & 47.1 & 24.9 & 0 & 0 & 20 & 100 \\
\hline & CRU & 31.7 & 35.2 & 98.5 & 44 & 31.7 & 0 & 0 & 23 & 100 \\
\hline \multirow[t]{4}{*}{ Lincoln, NE } & NCAR273 CCSM & 10.8 & 31.6 & 64 & 55.8 & 11.3 & 0 & 2.6 & 14.4 & 95.9 \\
\hline & CSIRO MARK 3.0 & 12.2 & 28.6 & 91.7 & 57.2 & 18.8 & 0 & 40.8 & 16.7 & 65.7 \\
\hline & MIROC-H & 15.9 & 30.3 & 77.6 & 54.5 & 16.3 & 0 & 1.9 & 18.8 & 98.1 \\
\hline & CRU & 21.3 & 39 & 70.3 & 52.5 & 21.3 & 0 & 0 & 24.3 & 100 \\
\hline \multirow[t]{4}{*}{ Lubbock, TX } & NCAR273 CCSM & 14.1 & 37.4 & 96.2 & 43.7 & 18.1 & 0 & 50.1 & 13.8 & 58.3 \\
\hline & CSIRO MARK 3.0 & 5.2 & 34.8 & 98.6 & 44.2 & 15.5 & 0 & 167.7 & 11.5 & 21 \\
\hline & MIROC-H & 9.5 & 33.9 & 97.5 & 47.3 & 17.9 & 0 & 95 & 13.4 & 40.2 \\
\hline & CRU & 30.6 & 39.3 & 98.7 & 57.1 & 31.1 & 0 & 1.6 & 22.1 & 98.4 \\
\hline
\end{tabular}

general circulation models on population distribution and relative abundance across North America.

\section{Methods}

The bioclimatic model for M. sanguinipes, developed using CLIMEX 2.0 [19], has been previously described [17]. CLIMEX is a dynamic model that integrates the weekly responses of a population to climate using a series of annual indices. It uses an annual Growth Index to describe the potential for population growth as a function of soil moisture and temperature during favourable conditions, and Stress Indices (cold, wet, hot, and dry) to determine the effect of abiotic stress on survival in unfavourable conditions. The weekly Growth Index is a function of temperature (TI), diapause (DI), and moisture (MI). The growth and stress indices are calculated weekly and then combined into an overall annual index of climatic suitability, the Ecoclimatic Index (EI), that ranges from 0 for locations at which the species is not able to persist to 100 for locations that are optimal for the species [17]. Model parameter values are listed in Table 1. Initial parameter values were obtained from published papers. Model parameters were then adjusted to ensure that EI $\geq 30$ in geographical regions historically affected by $M$. sanguinipes, indicating that climatic conditions were favorable for development of densities associated with crop loss. Historical grasshopper population data were used for model validation. Annual surveys of abundance of adult grasshoppers have been conducted in Saskatchewan since 1931 [20]. Relative abundance was validated by comparison with adult grasshopper survey data from Saskatchewan over the period of 1970 to 2004 [17]. The model was tested by comparing the occurrence of observed life history events against those predicted by the model.

Climate change projections were obtained from the Intergovernmental Panel on Climate Change [21] as monthly means for three GCMs, based on current climate, $30 \mathrm{yr}$ average (1961-1990) dataset (A1B emission scenario) (CRUClimate Research Unit, East Anglia, UK). The three GCMs selected were CSIRO Mark 3.0 (CSIRO, Australia), NCAR273 CCSM (National Centre for Atmospheric Research, USA), and MIROC-H (Centre for Climate Research, Japan). All three had relatively small horizontal grid spacing and the requisite climatic variables at a temporal resolution appropriate for CLIMEX. The data were pattern-scaled to develop individual change scenarios relative to the base 


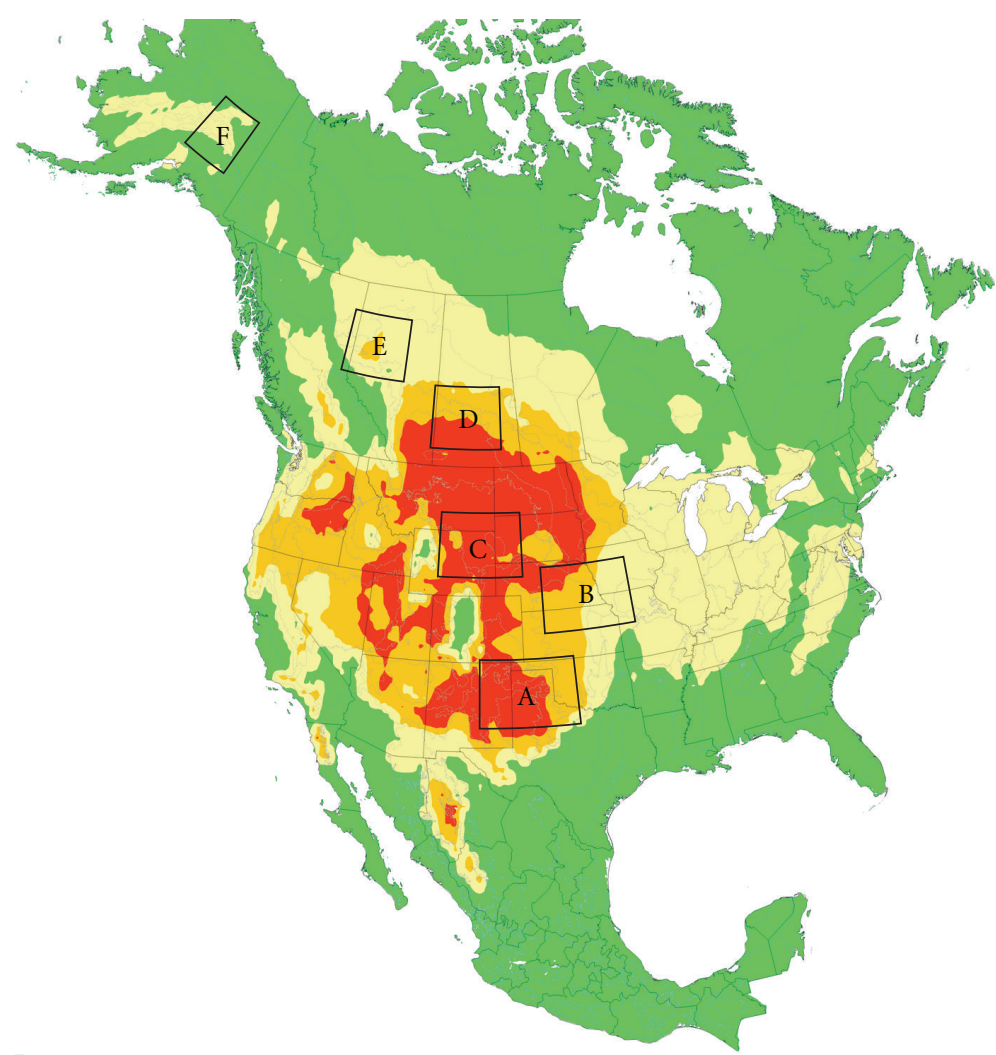

FIGURE 1: Predicted distribution and abundance (EI) of Melanoplus sanguinipes for current climate (CRU) at six regions: (A) Lubbock, TX; (B) Lincoln, NE; (C) Gillette, WY; (D) Saskatoon, SK; (E) Peace River, AB; (F) Fairbanks, AK. Green = "Unfavourable" (EI = 0-5); Tan = "Suitable" (EI = 5-20); Orange = "Favourable" (EI = 20-30); Red = "Very Favourable" (EI $\geq 30)$.

climatology [22]. The three models cover a range of climate sensitivity, defined as the amount of global warming for a doubling of the atmospheric $\mathrm{CO}_{2}$ concentration compared with 1990 levels [23]. The respective sensitivities are: CSIRO Mark $3.0\left(2.11^{\circ} \mathrm{C}\right)$, NCAR-CCSM $\left(2.47^{\circ} \mathrm{C}\right)$, and MIROC-H $\left(4.13^{\circ} \mathrm{C}\right)$.

The resulting database was queried to analyze data at a regional scale. A geographic rectangle, $4^{\circ}$ latitude by $7^{\circ}$ longitude, was used to delineate a regional template. The defined region was approximately the size and shape of Colorado $\left(270,000 \mathrm{~km}^{2}\right)$ and, for each of the datasets, consists of 112 grid cells. Specific regions, based on latitude and longitude coordinates, were defined and output (averaged across the region) was generated for detailed analysis. The datasets permitted comparison of variables, both spatially and temporally (weekly intervals). Analyses were based on values centered on six locations including Lubbock, Texas $\left(33.6^{\circ} \mathrm{N}, 101.9^{\circ} \mathrm{W}\right)$, Gillette, Wyoming $\left(44.3^{\circ} \mathrm{N}, 105.5^{\circ} \mathrm{W}\right)$, Lincoln, Nebraska $\left(40.9^{\circ} \mathrm{N}, 96.7^{\circ} \mathrm{W}\right)$, Saskatoon, Saskatchewan $\left(52.1^{\circ} \mathrm{N}, 106.6^{\circ} \mathrm{W}\right)$, Peace River, Alberta $\left(56.2^{\circ} \mathrm{N}, 117.3^{\circ} \mathrm{W}\right)$, and Fairbanks, Alaska $\left(64.8^{\circ} \mathrm{N}\right.$, $\left.147.7^{\circ} \mathrm{W}\right)$.

Contour maps were generated by importing EI values into geographic information system software, ArcView 8.1 [24]. Final EI values were displayed in the four categories defined above: "Unfavourable," "Suitable;" "Favourable;" and "Very Favourable."

\section{Results and Discussion}

Comparisons were made to determine if differences in baseline climate data would result in differences in output. The New et al. [25] climate data represents a splined $0.5^{\circ}$ world grid dataset. The EI output the baseline CRU data agreed with that produced using the New et al. [25] climate data set in Olfert and Weiss [17]. Initially, there appeared to be some differences in model output between the two approaches for Peace River and Saskatoon (Table 2). Olfert and Weiss [17] reported that the EI values for Peace River and Saskatoon were 24 and 30, respectively. This study showed that EI values for Peace River and Saskatoon were 14.7 and 26.7 (Table 2). These differences occurred because the original paper reported values for single grid cells. However, the current analysis was based on averages across large regions that are composed of 112 grid cells. When single grid cells for Peace River and Saskatoon were examined in the current study, it was found that EI values were indeed 24 and 30.

Results, based on the CRU data for current climate, indicated that M. sanguinipes would have highest EI values across 


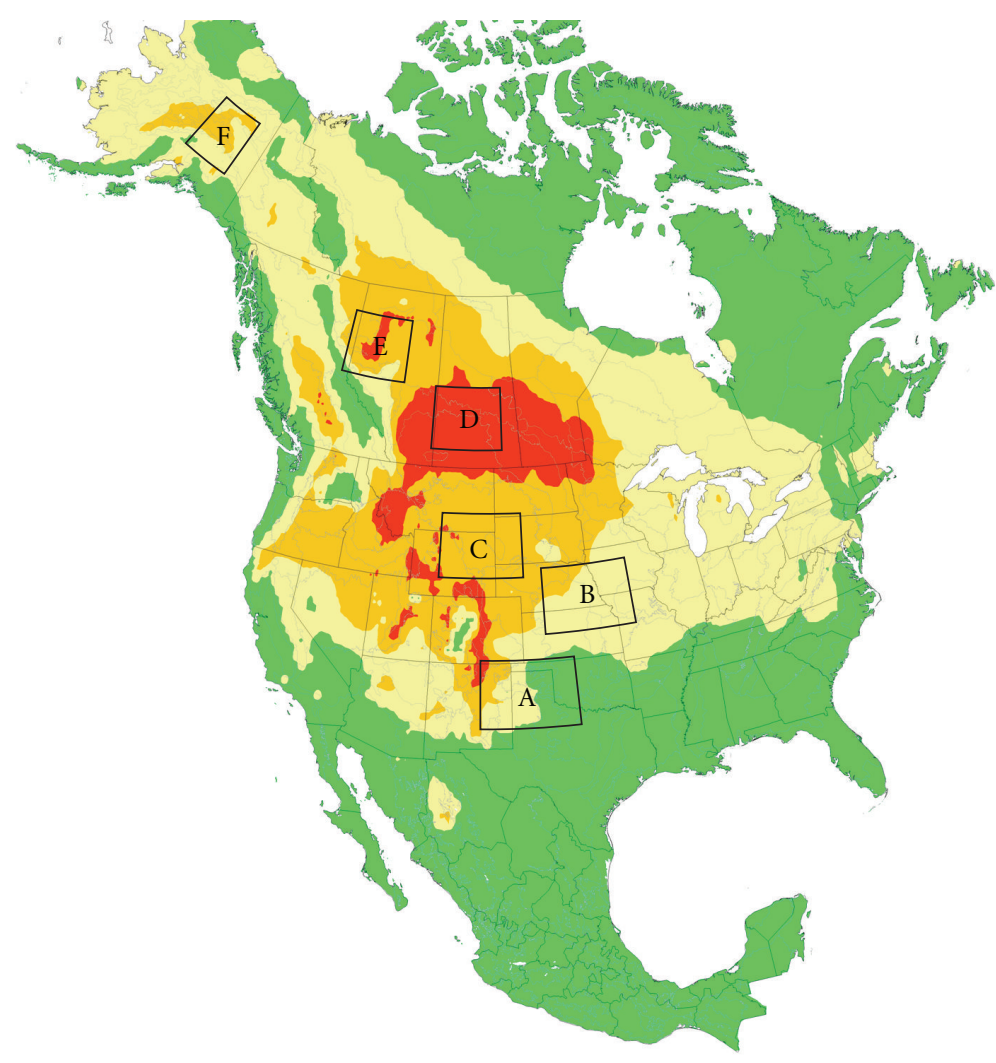

FIGURE 2: Predicted distribution and abundance (EI) of Melanoplus sanguinipes for 2080 (CSIRO MARK 3.0) at six regions: (A) Lubbock, TX; (B) Lincoln, NE; (C) Gillette, WY; (D) Saskatoon, SK; (E) Peace River, AB; (F) Fairbanks, AK. Green = "Unfavourable" (EI = 0-5); Tan = "Suitable" (EI = 5-20); Orange = "Favourable" $(\mathrm{EI}=20-30)$; Red = "Very Favourable" (EI $\geq 30)$.

most of the Great Plains of North America, extending from northern Texas to southern Saskatchewan (Figure 1). These results agreed with the distribution of $M$. sanguinipes as described by Riegert [20] and Pfadt [26]. Compared to these results, each of the three GCMs resulted in large differences for most model parameters, particularly EI (Figures 2-4; Table 2). Across North America, the overall mean EI values were 4.9 (CRU), 7.5 (CSIRO MARK 3.0), 7.9 (MIROC-H), and 7.3 (NCAR273 CCSM). Olfert and Weiss [17] grouped ecoclimatic indices into four categories: "Unfavourable" (EI $=0-5)$, "Suitable" $(\mathrm{EI}=5-20)$, "Favourable" $(\mathrm{EI}=20-30)$, and "Very Favourable" (EI $\geq 30)$. Unfavourable described regions where $M$. sanguinipes would be very rare or may not occur; "Suitable" defined areas were grasshoppers would occur, usually in low densities; "Favourable" defined areas were densities could be high enough to result in crop loss; "Very Favourable" defined areas where grasshoppers regularly occur in high enough densities that result in crop loss. Based on this study, the extent of the area predicted to be "Very Favourable" were 11.2\% (CRU), 16.2\% (CSIRO MARK 3.0), $16.2 \%$ (MIROC-H), and $18.1 \%$ (NCAR273 CCSM) of North America.

Species are more vulnerable to variations in temperature and precipitation when located near the outer limits of their geographic range than when located in the core area of the range. Sutherst et al. [19] defined a core area as a region with high EI values and little or no stress. Populations near the outer limits of the core area spend a greater amount of time in climates that are marginally suitable (exposed to climatic stress), while populations near the core experience a greater amount of time in favourable conditions (minimal exposure to climatic stress). In this study, EI values tended to increase in a northwestern direction and decrease for southern locations when the three GCMs were applied to the bioclimate model for $M$. sanguinipes. The percent of area (on a regional basis) with EI $\geq 20$ varied across North America. For example, under current climate conditions (CRU), the model predicted that $0 \%$ of the Fairbanks region had EI $\geq 20$ (Table 3). This value increased to as much as $57 \%$ of the area under conditions predicted by NCAR 273 CCSM. As a result, the increase in the biological suitability of Fairbanks, AK, due to climate change was predicted to be similar to that of Lincoln, NE, under current climate conditions (CRU). In turn, the model predicted that the area surrounding Lincoln, NE, where EI $\geq 20$ would decrease to $6.3 \%$ (NCAR273 CCSM), compared to $59.8 \%$ under current climate conditions (CRU).

As indicated, there were regional differences across North America in output of the bioclimate model for $M$. sanguinipes when the three different GCMs were applied (Figures 2-4). The application of CSIRO MARK 3.0 climate data resulted in a northward shift of areas predicted to have 


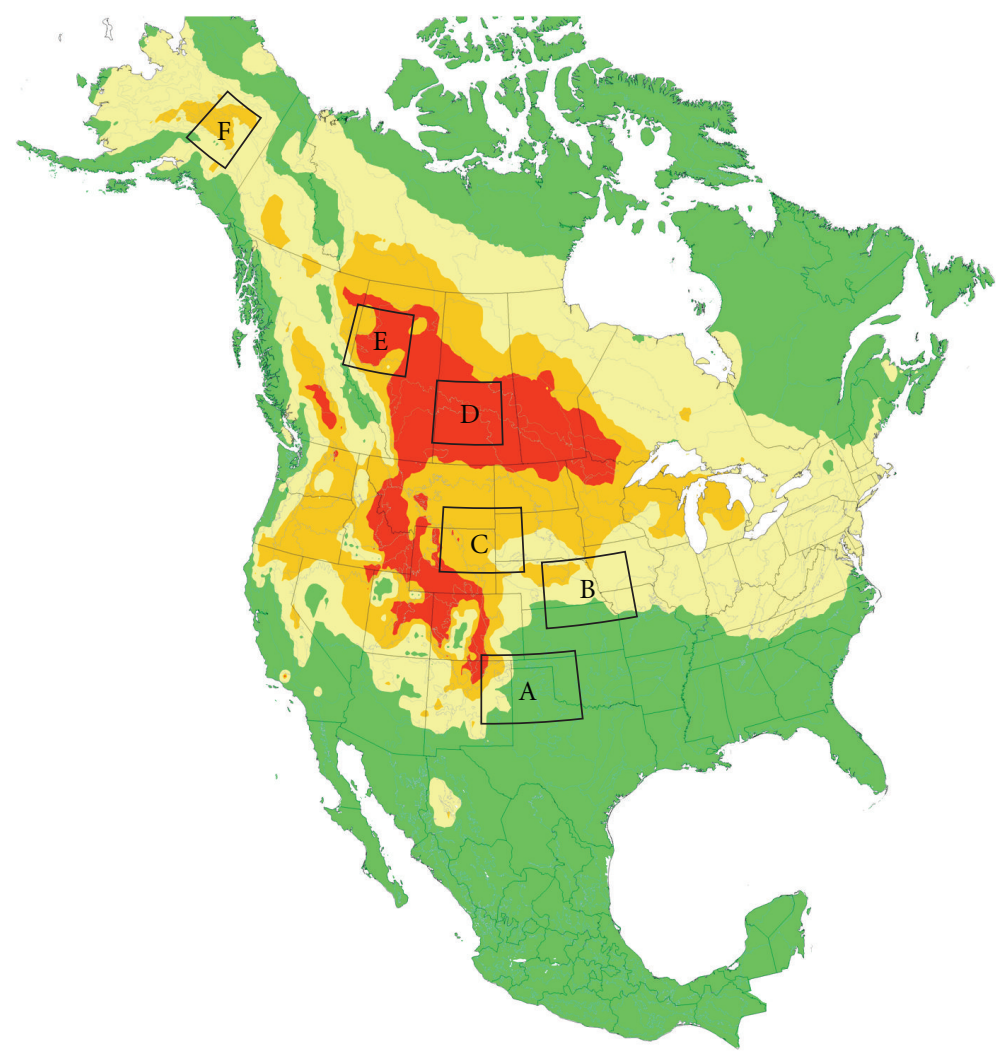

FIGURe 3: Predicted distribution and abundance (EI) of Melanoplus sanguinipes for 2080 (MIROC-H) at six regions: (A) Lubbock, TX; (B) Lincoln, NE; (C) Gillette, WY; (D) Saskatoon, SK; (E) Peace River, AB; (F) Fairbanks, AK. Green = "Unfavourable" (EI = 0-5); Tan = "Suitable" (EI = 5-20); Orange = "Favourable" (EI = 20-30); Red = "Very Favourable" (EI $\geq 30)$.

reduced suitability for grasshopper populations within the southern Great Plains, relative to current climate conditions (CRU). There was a significant reduction in EI values in states such as Colorado, Wyoming, and Missouri (Figure 2). In northwest Texas, the EI values were predicted to decrease to less than 10. In more northern regions, however, EI values were predicted to be higher in Alaska, northern Alberta, and Saskatchewan, relative to current climate conditions (CRU). Output based on the MIROC-H dataset resulted in a northwest shift of regions with $\mathrm{EI} \geq 20$ (Figure 3). Compared to current climate data (CRU), the MIROCH GCM predicted that the overall area suitable for $M$. sanguinipes in the USA would be less than under current climate conditions. However, the suitable areas along the Rocky Mountains were observed to increase somewhat. The MIROC-H dataset predicted large EI increases across most of the Canadian prairies, and extending northwest to include a continuous area northwest to Peace River, Alberta. Of the three GCMs, MIROC-H output resulted in the largest, continuous areas with $\mathrm{EI} \geq 20$. Unlike CSIRO MARK 3.0 and MIROC-H, NCAR273 CCSM predicted a reduction in EI values for eastern North America. This GCM also predicted increased EI values in the interior of British Columbia.

In order to assess the potential impact of climate change in a more regional context, the resulting database was queried to analyze data at six regional locations between
Lubbock, Texas, and Fairbanks, Alaska. Overall, the largest differences in EI values were observed at northern and southern regions of North America. The shifts in EI values were less in central locations. Compared to current climate (CRU), EI values derived from GCMs resulted in increased EI for the areas surrounding the three northern regions Saskatoon, Peace River, and Fairbanks (Figures 1-4, Table 2). The magnitude of the increase in EI values, based on regional means, was $252 \%, 77 \%$, and $33 \%$ greater for Fairbanks, Peace River, and Saskatoon, respectively, than those under current climate conditions. As a result, warming conditions were predicted to result in increased potential for M. sanguinipes outbreaks in these three regions. Outbreaks of $M$. sanguinipes have been recently reported in northern areas of North America. This species has been reported to be a sporadic, potentially damaging grasshopper pest of small grain crops in Alaska [27] and recent outbreaks of grasshoppers have been reported in the Peace River region of Alberta [28]. The three southern locations (Lincoln, Gillette, and Lubbock) had lower EI values when GCMs were used as inputs into the model. Relative to the EI values under current climate, the regional mean EI values for Gillette, Lincoln, and Lubbock were predicted to be $23 \%, 29 \%$, and $69 \%$ less, respectively. The regional responses to model input varied for the three GCMs (Table 3). The MIROC-H GCM resulted in the largest increase in EI for the Peace River and Saskatoon regions, 


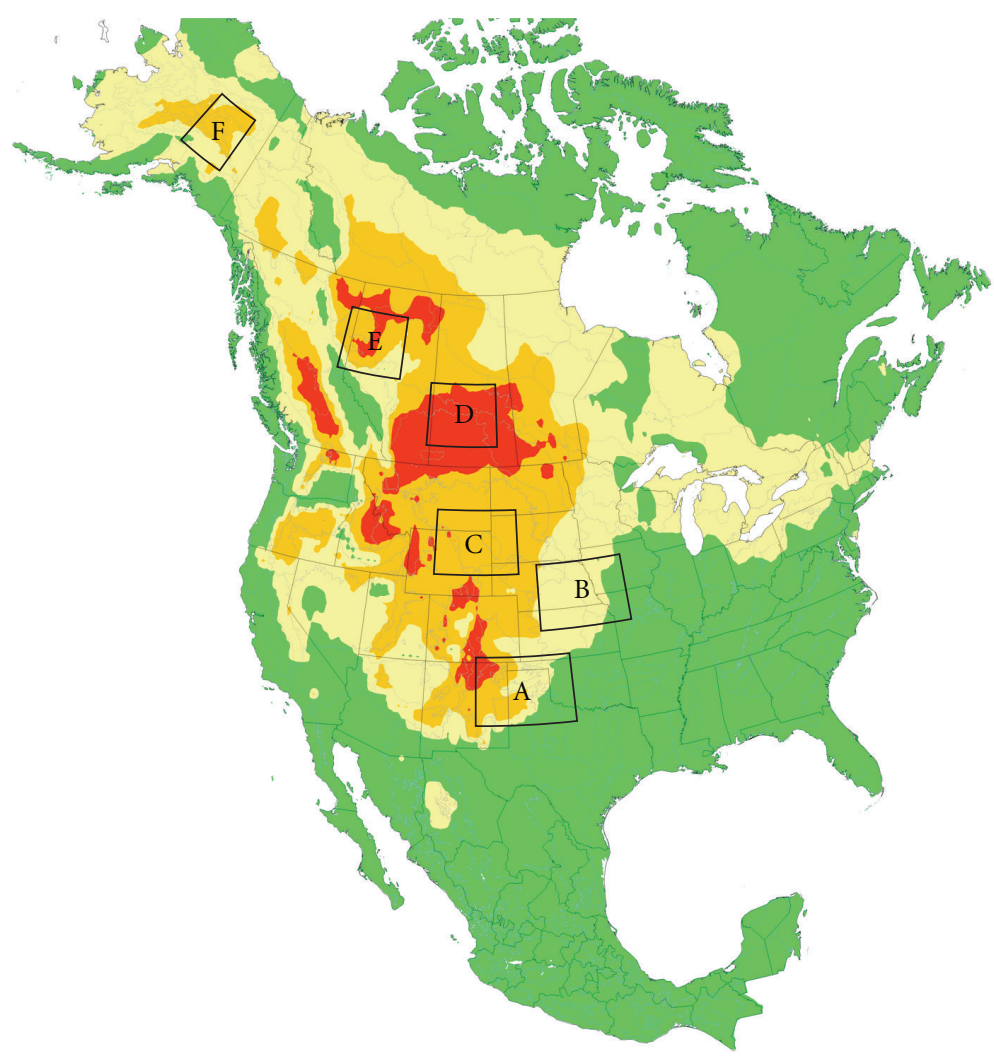

FIGURE 4: Predicted distribution and abundance (EI) of Melanoplus sanguinipes for 2080 (NCAR273 CCSM) at six regions: (A) Lubbock, TX; (B) Lincoln, NE; (C) Gillette, WY; (D) Saskatoon, SK; (E) Peace River, AB; (F) Fairbanks, AK. Green = "Unfavourable" (EI = 0-5); Tan = "Suitable" (EI = 5-20); Orange = "Favourable" $(\mathrm{EI}=20-30)$; Red = "Very Favourable" (EI $\geq 30)$.

while the NCAR273 CCSM model resulted in the largest increase for the Fairbanks region. Of the three more southern regions, Lubbock exhibited the largest decrease in EI values for MIROC-H.

The weekly temperature index (TI) describes the weekly response of $M$. sanguinipes to the daily temperature cycles that occur during the growing season. Melanoplus sanguinipes overwinters in the egg stage. The timing and duration of spring hatch is influenced by the level of embryonic development going into winter, natural enemies, and soil temperature and moisture $[29,30]$. In northerly regions, $M$. sanguinipes produces only one generation per year; in more southerly areas, a small proportion of the eggs oviposited do not enter diapause and may result in a lesser second generation. This species prefers warm, dry weather conditions. Warm temperatures early in spring favour nymphal development and in turn the timing of adulthood. Conversely, cool and wet conditions in spring results in increased nymphal mortality and delayed development. Crop loss due to feeding damage can occur throughout the growing season. Newly emerged seedlings in spring are most vulnerable, however, gradual plant defoliation may also contribute to decreased crop yield and quality $[14,16]$. Later in the growing season, an extended, warm fall influences the longevity of adults, allowing them to continue reproducing until freeze-up $[29,30]$. As a result, economic infestations are often associated with a prolonged period of consecutive seasons with above-normal temperatures [29]. Intermittent warm seasons tend to result in fluctuating populations [ 31 , 32]. The GCM datasets, associated with temperatures that are warmer than CRU values, resulted in increased TI values for northern regions and reduced TI for southern regions. Olfert and Weiss [17] reported that incremental scenarios of $+2^{\circ} \mathrm{C}$ and $+4^{\circ} \mathrm{C}$ resulted in increased TI values and increases in both EI and the potential area of Canada that would potentially be exposed to grasshopper outbreaks. At Fairbanks, TI values increased from 12.0 (CRU) to 20.1 (NCAR273 CCSM), resulting in more favourable temperatures during the growing season. Changes in central North America were less dramatic. Temperature indices in the Saskatoon region were predicted to increase from 30.7 (CRU) to 37.8 (NCAR273 CCSM). Excessively warm temperatures have been shown to hinder grasshopper populations [29, 33]. Output indicates that increased temperatures would result in higher heat stress (HS) values in northern Texas and Nebraska.

The growth index (GI) is a weekly thermo hydrological index that describes conditions that are favourable for growth. CLIMEX outputs the number of weeks where the growth index is nonzero, effectively determining the length of the growing season. Growing season length and cold stress accumulation are two factors that limit the potential 
TABLE 3: Baseline (CRU) and general circulation model (NCAR273 CCSM, MIROC-H, and CSIRO MARK 3.0) scenarios and percent of area with EI values greater than, or equal to, 20 for Melanoplus sanguinipes at six locations in North America.

\begin{tabular}{|c|c|c|}
\hline Location & GCM Scenario & $\begin{array}{c}\% \text { of area with } \\
\text { EI } \geq 20\end{array}$ \\
\hline \multirow[t]{4}{*}{ Fairbanks, AK } & NCAR273 CCSM & 57.1 \\
\hline & CSIRO MARK 3.0 & 48.2 \\
\hline & MIROC-H & 49.1 \\
\hline & CRU & 0 \\
\hline \multirow[t]{4}{*}{ Peace River, $\mathrm{AB}$} & NCAR273 CCSM & 75.6 \\
\hline & CSIRO MARK 3.0 & 85.2 \\
\hline & MIROC-H & 94.1 \\
\hline & CRU & 19.3 \\
\hline \multirow[t]{4}{*}{ Saskatoon, SK } & NCAR273 CCSM & 100 \\
\hline & CSIRO MARK 3.0 & 100 \\
\hline & MIROC-H & 100 \\
\hline & CRU & 92 \\
\hline \multirow[t]{4}{*}{ Gillette, WY } & NCAR273 CCSM & 100 \\
\hline & CSIRO MARK 3.0 & 100 \\
\hline & MIROC-H & 88.1 \\
\hline & CRU & 100 \\
\hline \multirow[t]{4}{*}{ Lincoln, NE } & NCAR273 CCSM & 6.3 \\
\hline & CSIRO MARK 3.0 & 25.9 \\
\hline & MIROC-H & 23.2 \\
\hline & CRU & 59.8 \\
\hline \multirow[t]{4}{*}{ Lubbock, TX } & NCAR273 CCSM & 40.7 \\
\hline & CSIRO MARK 3.0 & 24.4 \\
\hline & MIROC-H & 12.6 \\
\hline & CRU & 98.5 \\
\hline
\end{tabular}

for population growth in the Fairbanks region. Increased temperatures were predicted to not only decrease the rate of cold stress accumulation, but to also increase both the diapause index (DI) and the length of the growing season from 14 weeks to 17-18 weeks. The growing season in the Peace River region was predicted to increase from 19 weeks to 22 weeks and would result in a growing season that is similar to the current growing season in the Saskatoon region. Mills [34] predicted that regions north of $55^{\circ} \mathrm{N}$ and west of $110^{\circ} \mathrm{W}$ have soils that are suitable for agricultural production and that climate change could positively impact small grain production in the area. This would suggest that $M$. sanguinipes populations could become established in these new agricultural areas in the event that they become accessible in the future. In southern regions, however, mean GI values and the number of weeks where GI values were positive decreased. Output indicated that prolonged periods of warm temperatures during the growing season could limit potential for grasshopper population growth. Extreme heat and drought tends to reduce crop growth while increase grasshopper feeding activity. Mukerji et al. [32] reported that increased competition for food can also result in population decline due to high mortality because of starvation.
In conclusion, bioclimatic models have proven useful for studies investigating the potential impact of climate on insect populations. However, some cautions have been expressed regarding the utilization of this approach including: (i) biotic interactions may not remain the same over time (adaptation can, and is likely to, occur); (ii) genetic and phenotypic composition of populations may change over time and space; (iii) most species have some limitation to dispersal $[35,36]$. In the instance of $M$. sanguinipes, the impact of biotic factors such as natural enemies (e.g., diseases, parasites) must also be considered. For example, termination of several grasshopper outbreaks in Canada were attributed to cool, wet weather and epizootics of Entomophthora grylli Fres. [20,37]. Even though conditions may be predicted to be conducive to grasshopper populations under climate change, diseases could result in population decline. In these instances, bioclimate and GCMs may not account for changes in population, and may overestimate populations. To address these naturally occurring phenomena, bioclimate modeling of grasshopper populations will benefit from a multitrophic approach (host plants—grasshoppers—natural enemies).

\section{Acknowledgment}

D. Giffen is gratefully acknowledged for preparation of the maps.

\section{References}

[1] R.W. Sutherst, "Climate change and invasive species-a conceptual framework," in Invasive Species in a Changing World, H. A. Mooney and R. J. Hobbs, Eds., pp. 211-240, Island Press, Washington, DC, USA, 2000.

[2] C. Rosenzweig, A. Iglesias, X. B. Yang, P. R. Epstein, and E. Chivian, "Climate change and U.S. Agriculture," in The Impacts of Warming and Extreme Weather Events on Productivity, Plant Diseases, and Pests, Center for Health and Global Environment, Harvard University Press, Cambridge, Mass, USA, 2000.

[3] S. Cohen and K. Miller, "North America," in Climate Change 2001: Impacts, Adaptation, and Vulnerability, J. J. McCarthy, O. F. Canziani, N. A. Leary, D. J. Dokken, and K. S. White, Eds., pp. 737-800, Cambridge University Press, Cambridge, UK, 2001.

[4] G.-R. Walther, E. Post, P. Convey et al., "Ecological responses to recent climate change," Nature, vol. 416, no. 6879, pp. 389395, 2002.

[5] T. L. Root, J. T. Price, K. R. Hall, S. H. Schneider, C. Rosenzweig, and J. A. Pounds, "Fingerprints of global warming on wild animals and plants," Nature, vol. 421, no. 6918, pp. 5760, 2003.

[6] H. Gitay, S. Brown, W. Easterling, and B. Jallow, "Ecosystems and their goods and services," in Climate Change 2001: Impacts, Adaptation, and Vulnerability, J. J. McCarthy, O. F. Canziani, N. A. Leary, D. J. Dokken, and K. S. White, Eds., pp. 237-242, Cambridge University Press, Cambridge, UK, 2001.

[7] J. H. Porter, M. L. Parry, and T. R. Carter, "The potential effects of climatic change on agricultural insect pests," Agricultural and Forest Meteorology, vol. 57, no. 1-3, pp. 221-240, 1991.

[8] R. W. Sutherst, T. Yonow, S. Chakraborty, C. O’Donnell, and N. White, "A generic approach to defining impacts of 
climate change on pests, weeds, and diseases in Australia," in Greenhouse: Coping with Climate Change, W. J. Bouma, G. I. Pearman, and M. R. Manning, Eds., pp. 281-307, CSIRO Publishing, Collingwood, Australia, 1996.

[9] K. A. Evans and J. M. Hughes, "Methods for predicting changes in pest distribution due to climate change: wheat bulb fly. Implications of 'global environmental change' for crops in Europe," Aspects of Applied Biology, vol. 45, pp. 285-292, 1996.

[10] D. W. McKenney, A. A. Hopkin, K. L. Campbell, B. G. Mackey, and R. Foottit, "Opportunities for improved risk assessments of exotic species in Canada using bioclimatic modeling," Environmental Monitoring and Assessment, vol. 88, no. 1-3, pp. 445-461, 2003.

[11] O. Olfert, R. M. Weiss, S. Woods, H. Philip, and L. Dosdall, "Potential distribution and relative abundance of an invasive cereal crop pest, Oulema melanopus (Coleoptera: Chrysomelidae), in Canada," The Canadian Entomologist, vol. 136, no. 2, pp. 277-287, 2004.

[12] R. W. Sutherst and G. Maywald, "A climate model of the red imported fire ant, Solenopsis invicta Buren (Hymenoptera: Formicidae): implications for invasion of new regions, particularly Oceania," Environmental Entomology, vol. 34, no. 2, pp. 317-335, 2005.

[13] R. W. Sutherst, G. F. Maywald, T. Yonow, and P. M. Stevens, CLIMEX ${ }^{\circledR}$ Predicting the Effects of Climate on Plants and Animals, CSIRO Publishing, Collingwood, Australia, 1999.

[14] O. Olfert, "What is the role of grassland vegetation in grasshopper population dynamics?" in Grasshoppers and Grassland Health, J. A. Lockwood, A. V. Latchininsky, and M. J. Sergeev, Eds., pp. 61-70, Kluwer Academic, Boston, Mass, USA, 2000.

[15] O. Olfert and R. M. Weiss, "Impact of grasshopper feeding on selected cultivars of cruciferous oilseed crops," Journal of Orthoptera Research, vol. 11, pp. 83-86, 2002.

[16] J. E. Onsager and O. Olfert, "What tools have potential for pest management of Acrididae?: a North American perspective," in Grasshoppers and Grassland Health, J. A. Lockwood, A. V. Latchininsky, and M. J. Sergeev, Eds., pp. 145-156, Kluwer Academic, Boston, Mass, USA, 2000.

[17] O. Olfert and R. M. Weiss, "Bioclimatic model of Melanoplus sanguinipes (Fabricius) (Orthoptera: Acrididae) populations in Canada and the potential impacts of climate change," Journal of Orthoptera Research, vol. 15, pp. 65-77, 2006.

[18] A. M. Mika, R. M. Weiss, O. Olfert, R. H. Hallett, and J. A. Newman, "Will climate change be beneficial or detrimental to the invasive swede midge in North America? Contrasting predictions using climate projections from different general circulation models," Global Change Biology, vol. 14, no. 8, pp. 1721-1733, 2008.

[19] R. W. Sutherst, G. F. Maywald, W. Bottomley, and A. Bourne, CLIMEX ${ }^{\circledR}$ Version 2 User's Guide, Hearne Scientific Software, Melbourne, Australia, 2004.

[20] P. W. Riegert, "A history of grasshopper abundance surveys and forecasts of outbreaks in Saskatchewan," Memoirs of the Entomological Society of Canada, vol. 52, pp. 1-99, 1968.

[21] IPCC, Climate Change 2007: The Physical Science Basis, Contribution of Working Group I to the Fourth Assessment Report of the Intergovernmental Panel on Climate Change, Cambridge University Press, Cambridge, UK, 2007.

[22] P. H. Whetton, K. L. McInnes, and R. N. Jones, Australian Climate Change Projections for Impact Assessment and Policy Application: A Review, CSIRO Marine and Atmospheric Research, Melbourne, Australia, 2005.
[23] D. J. Kritcos, N. S. Alexander, and S. M. Kolomeitz, "Predicting the potential geographic distribution of weeds in 2080," in Proceedings of the 15th Australian Weeds Conference, Weed Science Society of South Australia, Adelaide, Australia, 2006.

[24] ESRI Inc., ArcView, Version 8.1, Redlands, California: Environmental Systems Research Institute Incorporated, 2001.

[25] M. New, M. Hulme, and P. Jones, "Representing twentiethcentury space-time climate variability. Part I: development of a 1961-90 mean monthly terrestrial climatology," Journal of Climate, vol. 12, no. 2-3, pp. 829-856, 1999.

[26] R. E. Pfadt, "Field Guide to Common Western Grasshoppers," Wyoming Agricultural Experiment Station Bulletin 912 (modified from 2nd Edition for electronic publication), 1994, http://www.sdvc.uwyo.edu/grasshopper/fieldgde.htm.

[27] D. J. Fielding, "Developmental time of Melanoplus sanguinipes (Orthoptera: Acrididae) at high latitudes," Environmental Entomology, vol. 33, no. 6, pp. 1513-1522, 2004.

[28] O. Olfert, D. Giffen, and S. Hartley, "The 2009 Alberta, Saskatchewan and Manitoba grasshopper forecast," in 2008 Crop Variety Highlights and Insect Pest Forecasts, Technical Bulletin No. 2009-01, Saskatoon Research Centre, Saskatoon, Canada, 2009.

[29] R. Pickford, "Development, survival and reproduction of Camnula pellucida (Scudder) (Orthoptera: Acrididae) in relation to climatic conditions," The Canadian Entomologist, vol. 98, pp. 158-169, 1966.

[30] R. Pickford, "The effects of climatic factors on egg survival and fecundity in grasshoppers," in Proceedings of the International Study Conference on Current and Future Problems of Acridology, C. F. Hemming and T. H. C. Taylor, Eds., pp. 257-260, Centre for Overseas Pest Research, London, Uk, 1972.

[31] S. K. Gage and M. K. Mukerji, "A perspective of grasshopper population distribution in Saskatchewan and interrelationships with weather," Environmental Entomology, vol. 6, pp. 469-479, 1977.

[32] M. K. Mukerji, S. H. Gage, and R. L. Randell, "Influence of embryonic development and heat on population trend of three grasshopper species (Orthoptera: Acrididae) in Saskatchewan," The Canadian Entomologist, vol. 109, pp. 229236, 1977.

[33] J. R. Parker, "Some effects of temperature and moisture upon Melanoplus mexicanus mexicanus Saussure and Camnula pellucida (Scudder) (Orthoptera)," Montana Agricultural Experimental Station Bulletin, vol. 223, 1930.

[34] P. F. Mills, "The agricultural potential of northwestern Canada and Alaska and the impact of climatic change," Arctic, vol. 47, no. 2, pp. 115-123, 1994.

[35] J. M. Jeschke and D. L. Strayer, "Usefulness of bioclimatic models for studying climate change and invasive species," Annals of the New York Academy of Sciences, vol. 1134, pp. 124, 2008.

[36] R. G. Pearson and T. P. Dawson, "Predicting the impacts of climate change on the distribution of species: are bioclimate envelope models useful?" Global Ecology and Biogeography, vol. 12, no. 5, pp. 361-371, 2003.

[37] R. Pickford and P. W. Riegert, "The fungous disease caused by Entomophthora grylli Fres., and its effects on grasshopper populations in Saskatchewan in 1963," The Canadian Entomologist, vol. 96, pp. 1158-1166, 1964. 

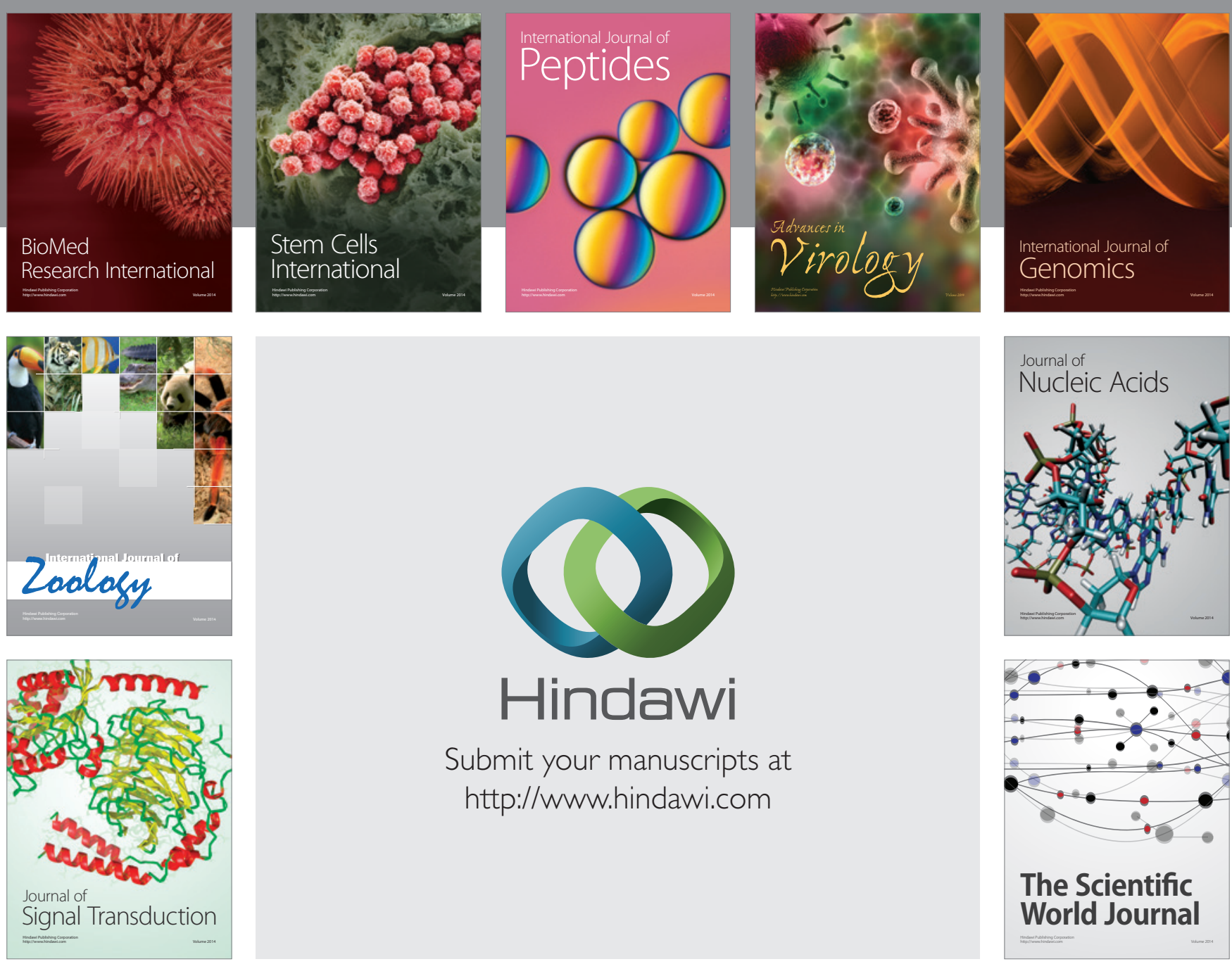

Submit your manuscripts at

http://www.hindawi.com
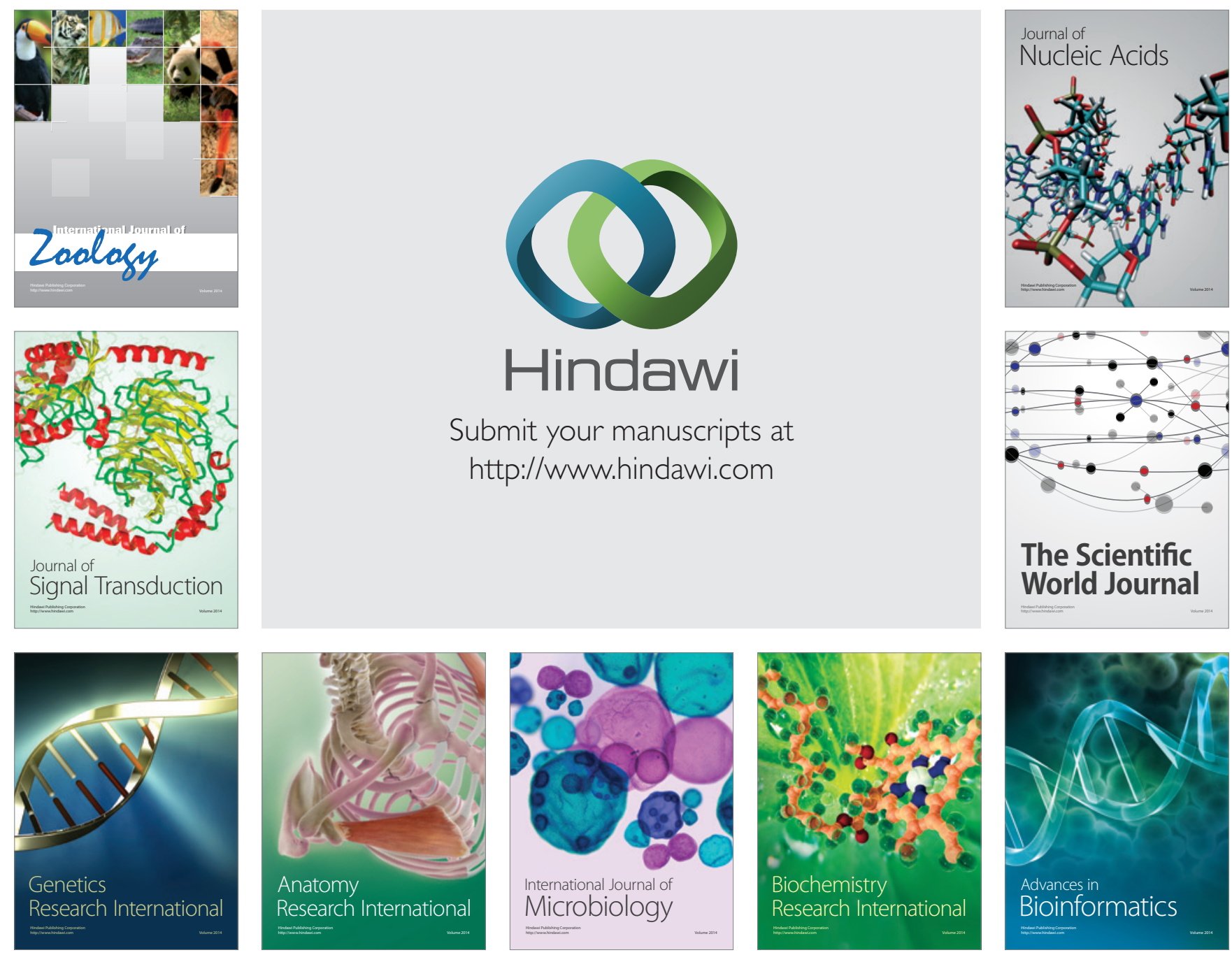

The Scientific World Journal
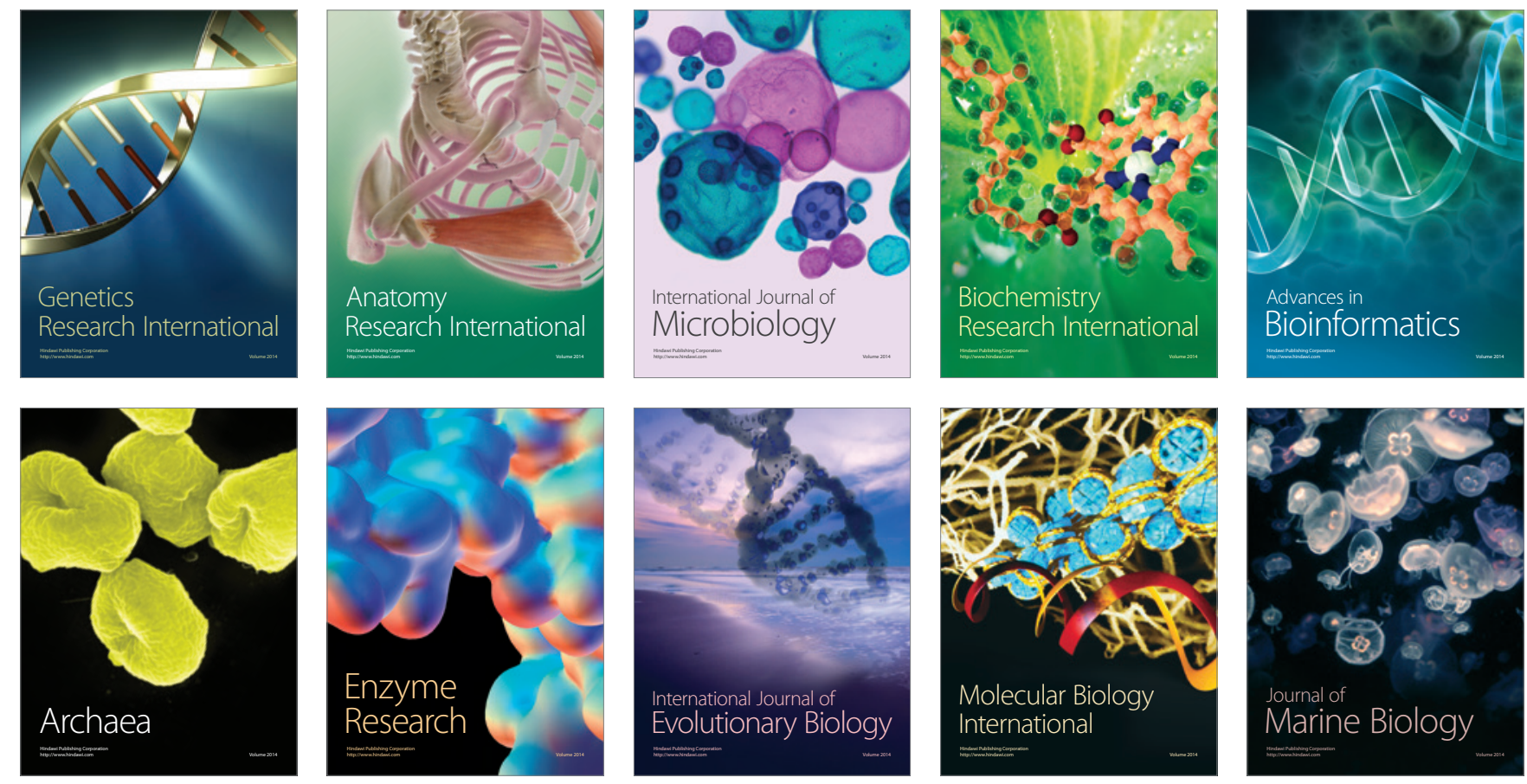